\title{
Evaluating nurse prescribers' education and continuing professional development for independent prescribing practice: Findings from a national survey in England
}

\author{
Sue Latter ${ }^{\mathrm{a}, *, 1}$, Jill Maben ${ }^{\mathrm{b}, 2,3}$, Michelle Myall ${ }^{\mathrm{a}, 4}$, Amanda Young ${ }^{\mathrm{a}, 5}$
}

a School of Nursing and Midwifery, Building 67, University of Southampton, Highfield, Southampton, Hampshire SO17 1BJ, England, UK

${ }^{\mathrm{b}}$ Health Services Research Unit, Department of Public Health and Policy, London School of Hygiene and Tropical Medicine, 32 Keppel Street, London WC1E 7HT, England, UK

Accepted 10 October 2006

\section{KEYWORDS}

Non-medical prescribing;

Nurse prescribing;

Education;

Continuing

professional

development

\begin{abstract}
Summary
Background: The number of nurses able to independently prescribe medicines in England has risen steadily in recent years.

Aim: To evaluate the adequacy of nurses' educational preparation for independent prescribing and to describe nurses' experiences of their continuing professional development as prescribers in practice.

Design and method: Postal questionnaire survey.

Participants: Random sample of 246 nurses registered as nurse independent prescribers with the Nursing and Midwifery Council.

Results: The majority of nurses considered that the initial taught course element of their education programme met their needs, either to some extent (61\% 151/246), or completely (22\% 54/246). Most nurses (77\% 190/246) received the specified 12 days support from their supervising medical practitioner and most were satisfied and positive about this experience. Nearly all of the nurses (>95\%) reported that they were able to maintain a range of specified prescribing competencies in
\end{abstract}

\footnotetext{
* Corresponding author. Tel.: +44 2380 597959; fax: +442380597900.

E-mail addresses: sml@soton.ac.uk (S. Latter), jill.maben@lshtm.ac.uk (J. Maben), m.myall@soton.ac.uk (M. Myall), ajy5@soton.ac.uk (A. Young).

1 T 02380597959 F 02380597900.

${ }^{2}$ Formerly School of Nursing and Midwifery, University of Southampton, Highfield, Southampton, Hampshire SO17 1BJ, England, UK.

3 T 02079272305.

${ }^{4}$ T 02380597634 F 02380597900.

${ }^{5}$ T 02380598478 F 02380597900.
} 
practice. Two thirds $(62 \% 152 / 246)$ of the sample reported that they were receiving support/supervision for prescribing. Ninety five per cent $(233 / 246)$ of the sample also reported that they engaged in self-directed informal continuing professional development, but only half of the sample had experience of formally provided professional development opportunities. Approximately half $(52 \% 127 / 246)$ of the sample identified needs for continuing professional development.

Conclusion: This first national survey of the education and professional development experiences of nurse independent prescribers in England provides evidence which highlights areas in which national policy is working well, and also points up issues which may need addressing as the roll out of nurse prescribing continues. The study also highlights characteristics and issues that health care policy makers and nurse educationalists internationally may wish to consider in developing and refining their own nurse prescriber education programmes.

(c) 2006 Elsevier Ltd. All rights reserved.

\section{Introduction}

In recent years in England, legislative authority to independently prescribe medicines has been extended to nurses working in a variety of clinical settings as part of the drive to modernize health care and make quality services accessible to all patients. Since 2002, nurses have been able to access a Nursing and Midwifery Council (NMC) approved education programme to prepare them to independently prescribe a specified range of medicines from the Nurse Prescribers' Extended Formulary (NPEF). ${ }^{6}$ In November 2005, the Department of Health in England announced that, from spring 2006, appropriately qualified nurses and pharmacists will be able to independently prescribe all licensed drugs, with the exception of some controlled drugs. This represents one of the most extensive developments of nonmedical prescribing anywhere in the world. But until recently, there had been no national evaluation of the adequacy of nurses' educational preparation for this role, and a lack of research investigation into the post-qualification professional development needs and experiences of nurse prescribers. Against this backdrop, the study reported in this paper was commissioned by the Policy Research Programme at the Department of Health in England.

\section{Background}

\section{The development of nurse prescribing}

The prescribing of medicines by nurses in England was piloted in the mid 1990s. Evaluation of the pilot sites (Luker et al., 1997, 1998) showed favourable findings across a range of indicators, from the perspectives of both patients and nurses. In 1999, the

\footnotetext{
${ }^{6}$ Details of the NPEF are set out in the British National Formulary and Part XV11B (ii) of the Drug Tariff.
}

Department of Health introduced a national training programme for some specialist community nurses (those with a district nurse and/or health visitor qualification) to train to prescribe dressings, appliances and a limited number of medicines from the Nurse Prescribers' Formulary (NPF). These developments in nurse prescribing have taken place in all four countries of the UK, with the devolved administrations in Scotland, Wales and Northern Ireland guiding the precise pace and detail of education, practice and policy on non-medical prescribing in each country. This expansion of prescribing powers to nurses also reflects international developments in nurse prescribing: in the United States of America, Canada, Sweden, Australia and New Zealand, legislation enabling nurses to prescribe a limited number of medicines has been in place for a number of years. In Sweden for example, nurses working in primary care and health care for older people have been able to prescribe from a limited formulary of medicines since the mid-1990s (Buchan and Calman, 2004). (For an overview of international developments in nurse prescribing, see Buchan and Calman, 2004.)

In England in 2002, nurse prescribing was extended to cover not just those nurses with a district nurse and/or health visitor qualification, but also a wider range of nurses who, after successful completion of a longer training programme, were able to independently prescribe over 180 Prescription Only Medicines (POMs), all General Sales List (GSL) and Pharmacy (P) medicines for around 80 clinical conditions. ${ }^{7}$ Independent prescribing has

\footnotetext{
7 This data was correct at the time that the research reported here was conducted. From May 2005, qualified independent nurse prescribers were able to prescribe from a list of around 240 POMs and all GSL and P medicines for around 110 clinical conditions listed in the Nurse Prescribers' Extended Formulary (NPEF). Since May 2006, nurse independent prescribers have been able to prescribe all medicines from the British National Formulary, with the exception of some controlled drugs.
} 
been defined as where 'the prescriber takes responsibility for the clinical assessment of the patient, establishing a diagnosis and the clinical management required, as well as responsibility for prescribing where necessary, and the appropriateness of any prescription'. (Department of Health, 2004). The training to become an Extended Formulary Nurse Prescriber' (EFNP) consisted of 25 days taught content in a Higher Education Institution $(\mathrm{HEI})$, together with 12 days supervised practice in the clinical setting with a doctor, known as a supervising medical practitioner. EFNP was originally targeted at those nurses who were working in roles where they were likely to be able to independently complete an episode of care with the acquisition of prescribing powers (Department of Health, 2002). Entry to the programme was restricted to those with at least three years experience after initial nurse registration, and those who were able to study at degree level. The delivery of prescribing education programmes by HEls is based on curriculum requirements specified by the NMC (2006). The specified knowledge areas required for an independent nurse prescribing role are summarized as:

- Legislation that underpins prescribing.

- Team working principles and practice.

- Philosophy and psychology of prescribing.

- Up to date clinical and pharmaceutical knowledge.

- Principles of drug dosage, side effects, reactions and interactions.

- Communication, consent and concordance.

- Relationship of public health requirements to prescribing.

- The Code of Professional Conduct applied to prescribing.

- The lines of accountability at all levels for prescribing.

- Drug abuse and the potential for misuse.

- Requirements of record keeping.

- Lines of communication.

- Leadership skills.

- Roles of other prescribers.

- Relationship of prescribers to pharmacists.

- Clinical governance requirements in prescribing practice.

- Audit trails to inform prescribing practice.

Following successful completion of formal assessment by the $\mathrm{HEI}$, nurses registered their qualification (V200) on the professional register with the NMC.

Since 2003, both nurses and pharmacists have been eligible to prescribe as supplementary pre- scribers, defined as a prescribing partnership between an independent prescriber (doctor or dentist) and a supplementary prescriber to prescribe within an agreed patient-specific Clinical Management Plan (Department of Health, 2003). Training for independent and supplementary prescribing is now incorporated within a single preparation programme of a minimum of 26 days $\mathrm{HEI}$-based learning and 12 days in practice with a supervising medical practitioner. Nurses previously qualified as EFNPs are able to undertake a two day 'top up' training, successful completion of which enables them to practice as supplementary prescribers.

The requirements for both nurses themselves and the organizations who employ them in relation to continuing professional development (CPD) are also laid out in policy guidelines on non-medical prescribing. The Department of Health (2004) guidelines stipulate that prescribers will be expected to keep up-to-date with best practice in the management of the conditions for which they prescribe and the medicines in the NPEF. Additionally, the guidelines state that the employer should ensure that the practitioner has access to relevant education and training provision. A framework of nurse prescribing competencies (National Prescribing Centre, 2001), which builds on the NMC-specified competencies for the nurse prescribing training curriculum is also available as a tool to help both trainee and qualified prescribers reflect on practice and to identify their CPD needs.

\section{Research into nurse prescribers' education and professional development}

A review of previous research into nurse prescribing prior to the commencement of the study (see Latter and Courtenay, 2004), highlighted a number of education and CPD issues that warranted further investigation. One recurring issue concerned inadequacies in the pharmacology knowledge of district nurses and health visitors trained to prescribe in the first wave of nurse prescribers in England, and nurses' need for further training in this area (While and Rees, 1993; Otway, 2001, 2002; Sodha et al., 2002a,b). Whilst not focusing specifically on evaluating nurses' educational preparation for a prescribing role, both Luker et al. (1998) and Baird (2001) identified that district nurse and health visitor prescribers had initial anxiety about writing prescriptions related to feelings of uncertainty about making a correct diagnosis. This may have been reflective of inadequate educational preparation 
for an independent prescribing role and/or a lack of prior clinical experience in formulating diagnoses. However, the extent to which these problems have been overcome since the introduction of a longer training programme, with specified curriculum requirements focusing on up to date clinical and pharmaceutical knowledge, delivered to a wider group of nurses with different roles and types of clinical experience, had not been investigated prior to the start of the study reported here.

Following the recent announcement of the further extension of nurse and pharmacist prescribing powers, Avery and Pringle (2005, p. 1154) comment that, 'the current schemes for training nurse and pharmacist prescribers are too short to fully equip a professional for independent prescribing practice. It is essential that additional training, support and mentorship are available after such programmes'. The need for further education and professional development after qualifying as a prescriber was also highlighted in the literature review. In their earlier research into district nurse and health visitor prescribing, both Luker et al. (1997) and Brooks et al. (2001) comment on nurses' need for further training as expansions to the formulary are introduced. Humphries and Green's (2000) work on district nurse and health visitor prescribers and Bradley and Nolan's (2004) research focused on trainee EFNPs and found that keeping updated and maintaining knowledge and skills were identified as potentially important issues in both groups. Otway's $(2001,2002)$ survey of more experienced district nurse and health visitor prescribers confirms the importance of on-going support and development for prescribing in practice, and also sheds light on what is actually provided. Otway conducted a questionnaire survey of 241 nurses in one NHS trust and subsequently interviewed 12 nurse prescribers, some of whom had up to three years' experience of prescribing from the original NPF for district nurses and health visitors. She found that informal peer support through working in teams provided a major source of support, and that this often compensated for a lack of more formal clinical supervision and mentorship. Working in isolation in practice was found to exert a negative influence on prescribing, impacting on nurses' confidence to prescribe. Ninety five per cent of those surveyed reported that they did not have a mentor when they first began prescribing, although $48 \%$ did report access to clinical supervision that included discussion of their prescribing role. Limitations in access to CPD for all prescribing professionals is also a conclusion drawn by Harris et al. (2004) following their review of research into effective prescribing.

The role of doctors in supporting and supervising trainee and qualified nurse prescribers is also crucial to ensure nurses are well prepared for their prescribing practice. Despite the policy recommendations on the role that doctors should play in the education and supervision of EFINPs, the extent to which doctors fulfill this role in the reality of practice was also under-researched at the time of this study. District nurse and health visitor prescribers in both Otway's (2002) and Humphries and Green's (2000) studies reported that not all GPs were supportive or aware of their prescribing role. However, in a more recent small scale study by Avery et al. (2004), the satisfaction of facilitating nurse prescribing was one of the benefits of nurse prescribing reported by the purposive sample of 12 doctors interviewed. Nurse prescribers' experiences of supervision and support from doctors for their prescribing role was an issue that was further investigated in the study reported here.

Overall, the review of literature on nurse prescribing highlighted an absence of research investigating nurses' experiences of educational preparation and continuing professional development for an extended formulary prescribing role. Clearly, appropriate education and training and CPD are essential for effective prescribing and therefore research was required to evaluate the effectiveness of educational preparation and CPD to date for nurses prescribing independently in practice.

\section{Study design}

\section{Aims and objectives}

The overall aim of the study was to evaluate the expansion of nurse independent prescribing in England to inform future developments for prescribing in nursing and other health professions. This paper reports on the objectives of the study that were concerned with evaluating the adequacy of nurses' educational preparation for independent prescribing and their experiences of continuing professional development as prescribers in practice.

\section{Design}

A national survey of nurse independent prescribers in England using a postal questionnaire comprised the first phase of the study (for a detailed descrip- 
tion of the full study, see Latter et al., 2005). The survey was conducted in 2003.

\section{Methods}

A 54 item questionnaire was developed, containing both open and closed questions, to elicit data on nurses' views of key dimensions of independent prescribing education and practice. The questionnaire was constructed following a review of the literature (see above) which identified key issues related to nurses' educational preparation for prescribing that required further investigation. The draft questionnaire was also reviewed by expert individuals with nurse prescribing education, policy and practice experience. Individuals who reviewed the draft questionnaire included expert representatives from the National Prescribing Centre, The Royal College of Nursing, the Association for Nurse Prescribing and nurse prescribing education leads in Higher Education Institutions (HEls). A second draft was subsequently reviewed by members of the research project's Advisory Group which included a recently qualified nurse prescriber, doctors with an interest in nurse prescribing and Department of Health representatives. The use of literature reviews and expert review in the development of new data collection tools are recognised methods of enhancing face and content validity (DePoy and Gitlin, 1994). Written and verbal feedback on the draft questionnaires were incorporated into the design and content of a revised questionnaire which was then subjected to piloting.

The pilot study was conducted with 18 extended formulary nurse prescribers registered in 2002/ 2003 who were selected at random from the NMC database. Questionnaire evaluation sheets were also distributed to the pilot participants who were asked to provide comments on the form and content of the questionnaire and to identify any questions that were ambiguous or unclear. Twelve questionnaires $(67 \%)$ were returned, together with $10(56 \%)$ evaluation sheets. The piloting process confirmed the feasibility of using the questionnaire to ascertain nurse prescribers' views on a broad range of education and practice experiences. The data collected from the pilot study also confirmed the questionnaire's face and content validity in obtaining nurses' views on their educational preparation for prescribing and their experiences of CPD. Minor modifications were made following piloting, for example, a filter question was included at the beginning of the questionnaire for those who reported that they were not using their prescribing qualification at the time that the survey was conducted.

The questionnaire was distributed by post to the sample of nurse prescribers by the NMC on behalf of the research team. The nurse prescribers therefore remained anonymous to the research team unless they chose to disclose their identity on their return questionnaire. A covering letter explaining the purpose of the study, and outlining how anonymity and confidentiality of participants would be protected, was included with the questionnaire, together with a stamped addressed envelope for returning the questionnaire directly to the research team. A second mailing was sent to non-responders by the NMC approximately 4-6 weeks after the first mailing.

The final version of the questionnaire used in the main study comprised three sections: (1) Experiences before the EFNP course. (2) Experiences during the EFNP course. (3) Experiences after the EFNP course, including sub-sections on 'views on knowledge and competencies' and 'views on support and continuing professional development'. The findings reported below are those from the questionnaire items focused on educational experiences and CPD in Sections 2 and 3 of the questionnaire.

\section{Sample}

Four hundred nurse prescribers for the national survey were randomly selected from the NMC's database of approximately 500 nurse prescriber registrations for 2002/early 2003 in England. The period of 2002/early 2003 was chosen so as to ensure that, at the time of the survey, the sample of nurse prescribers targeted would have had at least six months of prescribing in practice. It was envisaged that this would enable nurse prescribers to meaningfully reflect on their educational preparation, its adequacy for on-going prescribing practice and would also allow them the opportunity to reflect on their continuing professional development needs and experiences.

\section{Ethical considerations}

During the course of the study, the Royal College of Nursing's (1998) research ethics guidelines were utilised as a framework to ensure that ethical issues were properly addressed by the research team. This included adequately informing all participants about the details of the research study, and using procedures to anonymise the data whilst stored and in any reported findings, and keeping the data secure and confidential. 


\section{Data analysis}

For responses to open ended questionnaire items, coding frameworks were devised inductively from the data, and a process of content analysis applied that included numerical quantification of responses where appropriate. Descriptive statistics were produced from analysis of the questionnaire data derived from both open ended and fixed choice items using Statistical Package for the Social Sciences (SPSS) Version 12.0 software.

\section{Results}

\section{Sample characteristics}

Of the 400 questionnaires distributed to qualified nurse independent prescribers, $285(71 \%)$ were returned. Of these, $39(14 \%)$ were not prescribing at the time of the survey; therefore 246 questionnaires were available for analysis. Respondents were working in senior nursing roles. The most common roles were: nurse practitioners $(56 \%$ $138 / 246)$, practice nurses $(10 \% 25 / 246)$, sister/ team lead positions $(7.5 \% 19 / 246)$ and nurse specialist roles $(6.5 \% 16 / 246)$. The sample of nurses in the survey also had a comparatively high level of academic qualifications: $60 \%(147 / 246)$ held a first degree, and $21 \%(51 / 246)$ had obtained a Masters level qualification. The most commonly stated area of practice was general practice/primary care (54\% 135/246), with smaller proportions also specifying a range of other service delivery roles located in primary care, such as walk-in centres (4.5\% $11 / 246)$, family planning (3\% 7/246) and minor injuries units $(2 \% 6 / 246)$. Other clinical areas that respondents were working in included Acci- dent and Emergency (5\% 12/246) and palliative care $(3 \% 8 / 246)$.

\section{Experiences during the EFINP course}

Fig. 1 outlines nurses' views on the extent to which the 25 days $\mathrm{HEl}$-based education programme met their needs as trainee nurse prescribers.

Fig. 1 illustrates that the majority of the sample considered that the taught programme met their needs, either 'to some extent' (61\% 151/ 245), or 'completely' (22\% 54/245), although a small minority were less satisfied with the taught programme as a preparation for prescribing. This finding concerning the adequacy of educational preparation was reinforced by responses to a Likert statement: 'I believe the EFINP course prepared me for my role as an EFINP'. 22\% $(54 / 246)$ strongly agreed, 48\% (119/246) agreed, $18 \%(44 / 246)$ were uncertain, 9\% (22/246) disagreed and $2 \%(4 / 246)$ strongly disagreed with this statement.

Nurse prescribers were asked to specify the three subjects most commonly studied during private/self-directed study. Table 1 shows the responses to this item. Over three quarters of those who responded (84\% 192/228) identified pharmacology as one of the top three most commonly studied subjects. Polypharmacy was identified by $23.5 \%(54 / 228)$ of the sample, legal and ethical issues by $23 \%(53 / 228)$, principles of prescribing by $22.5 \%(52 / 228)$ and anatomy and physiology/pathophysiology by $20.5 \%(47 / 228)$ of the sample.

Nurse prescribers were also asked about the amount of support they received from their supervising medical practitioner. Almost half (47\% 116/ $246)$ reported that they had received 'more than'

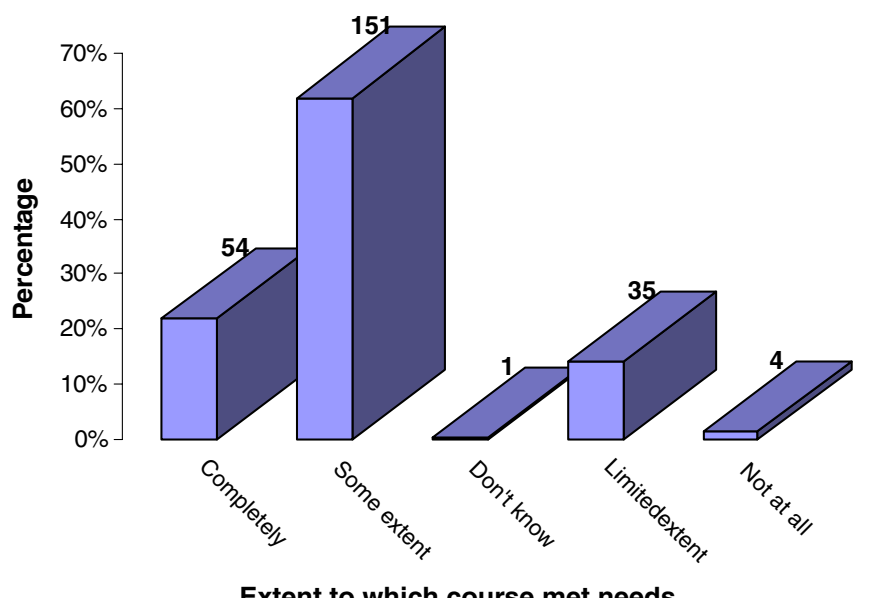

Extent to which course met needs 
Table 1 Topics reported as amongst the top three most commonly studied during private/self-directed study

\begin{tabular}{lc}
\hline Topics & $\begin{array}{l}\text { No. (\%) of } \\
\text { respondents } \\
(n=228)\end{array}$ \\
\hline Pharmacology & $192(84 \%)$ \\
Polypharmacy & $54(23.5 \%)$ \\
Legal and ethical issues & $53(23 \%)$ \\
$\begin{array}{l}\text { Principles of prescribing } \\
\text { (knowledge) }\end{array}$ & $52(22.5 \%)$ \\
A\&tP/pathophysiology & $47(20.5 \%)$ \\
Ailments/conditions & $40(17.5 \%)$ \\
Other (personal development) & $40(17.5 \%)$ \\
$\begin{array}{l}\text { Research (nurse prescribing) } \\
\text { BNF/medicines/NPEF/MIMS }\end{array}$ & $39(17 \%)$ \\
Prescribing related to own & $34(15 \%)$ \\
practice & $34(15 \%)$ \\
Clinical assessment/history & $30(13 \%)$ \\
$\quad$ taking & $4(1.5 \%)$ \\
\hline
\end{tabular}

Table 2 Level of satisfaction with supervising medical practitioner support

\begin{tabular}{lc}
\hline & $\begin{array}{c}\text { No. }(\%) \text { of respondents } \\
(n=246)\end{array}$ \\
\hline Very satisfactory & $77(31 \%)$ \\
Satisfactory & $126(51 \%)$ \\
Unsatisfactory & $31(13 \%)$ \\
Very unsatisfactory & $10(4 \%)$ \\
No response & $2(1 \%)$ \\
\hline
\end{tabular}

the specified 12 days, $30 \%$ (74/246) reported receiving 'exactly' 12 days and $23 \%(56 / 246)$ reported receiving 'less than' the specified 12 days support from their supervising medical practitioner. Table 2 shows the nurse prescribers' satisfaction with the amount of medical practitioner support that they had received during their preparation to become independent prescribers. This indicates that the majority $(82 \% 203 / 246)$ had found the level of support 'satisfactory' or 'very satisfactory', whilst a minority $(17 \% 41 / 246)$ were not satisfied with the support from their supervising medical practitioner.

Eighty five per cent (208) of the sample also responded to an item asking for comments about the quality of the medical practitioner support received. Sixty four per cent $(134 / 208)$ of these comments were positive: supervising medical practitioners were identified as 'supportive', 'excellent', 'non-threatening' and 'encouraging and enthusiastic'. However, 21\% (44/208) of responses identified the work commitments of their supervising doctors as prohibitive. A minority (14\% 30/208) of comments were also focused on other negative experiences, such as poor teaching skills and lack of support generally.

Respondents were invited to provide comments on the form of the support that they had received from their supervising medical practitioner. Ninety per cent (221) of the sample responded to this questionnaire item. Information was given on the method of delivery of their support as well as content. Methods most frequently identified included:

- observation of each other's surgeries (44\% 97/ 221),

- discussion of patient's interaction/assessment/ treatment/diagnosis (30\% 67/221),

- case study analysis ( $25 \% 55 / 221)$,

- tutorials/teaching (25\% 55/221).

In regard to the content of medical practitioner support, comments tended to be varied but some dominant themes emerged. These included:

- safe/guided prescribing decisions (56\% 123/221), - history taking/examination skills/diagnostic skills $(40 \% 88 / 221)$,

- aspects of pharmacology (14\% 30/221),

- reflective practice $(12 \% 26 / 221)$.

Respondents were asked to indicate whether they had received any other support in addition to their supervising medical practitioner whilst undertaking the EFNP course. Sixty three per cent $(156 / 246)$ of the sample stated that they had received other support, with $35 \%(87 / 246)$ reporting that this was not the case. Those respondents who had reported receiving other support in prac-

Table 3 Skills/knowledge needed for practice and not covered by EFNP course

\begin{tabular}{ll}
\hline Skills and knowledge $^{a}$ & $\begin{array}{l}\text { No. (\%) of } \\
\text { respondents } \\
(n=119)\end{array}$ \\
\hline Pharmacology & $46(39 \%)$ \\
Advanced clinical skills & $38(32 \%)$ \\
Physical assessments & $16(13 \%)$ \\
Skills related to practice area & $14(9 \%)$ \\
More information on the & $10(8 \%)$ \\
$\quad$ formulary & \\
\hline a Top five responses only. &
\end{tabular}


Table 4 Are nurse prescribers able to maintain National Prescribing Centre (2001) competencies in practice? $(n=246)$

\begin{tabular}{|c|c|c|c|c|c|c|}
\hline Statement & Strongly agree & Agree & Uncertain & Disagree & Strongly disagree & No answer \\
\hline I have up to date clinical knowledge & $53 \%(n=131)$ & $46 \%(n=113)$ & $1 \%(n=2)$ & 0 & 0 & 0 \\
\hline $\begin{array}{l}\text { I have up to date pharmacological } \\
\text { knowledge }\end{array}$ & $39.5 \%(n=97)$ & $55.5 \%(n=137)$ & $5(n=12)$ & 0 & 0 & 0 \\
\hline $\begin{array}{l}\text { I am able to make a diagnosis and } \\
\text { generate treatment options }\end{array}$ & $55 \%(n=135)$ & $44 \%(n=109)$ & $1 \%(n=2)$ & 0 & 0 & 0 \\
\hline $\begin{array}{l}\text { I always follow up treatment when } \\
\text { appropriate }\end{array}$ & $58 \%(n=144)$ & $40 \%(n=98)$ & $1 \%(n=2)$ & $0.5 \%(n=1)$ & 0 & $0.5 \%(n=1)$ \\
\hline $\begin{array}{l}\text { I am able to establish a relationship } \\
\text { with patients based on trust and } \\
\text { respect }\end{array}$ & $67.5 \%(n=166)$ & $31.5 \%(n=78)$ & $1 \%(n=2)$ & 0 & 0 & 0 \\
\hline $\begin{array}{l}\text { I see patients as partners in the } \\
\text { consultation }\end{array}$ & $72 \%(n=177)$ & $27 \%(n=66)$ & $1 \%(n=3)$ & 0 & 0 & 0 \\
\hline I apply the principles of concordance & $66 \%(n=163)$ & $33 \%(n=81)$ & $1 \%(n=2)$ & 0 & 0 & 0 \\
\hline $\begin{array}{l}\text { I work within professional and } \\
\text { organisational standards }\end{array}$ & $73 \%(n=180)$ & $26.5 \%(n=65)$ & $0.5 \%(n=1)$ & 0 & 0 & 0 \\
\hline $\begin{array}{l}\text { I take personal responsibility for } \\
\text { prescribing decisions }\end{array}$ & $78.5 \%(n=193)$ & $21.5 \%(n=53)$ & 0 & 0 & 0 & 0 \\
\hline $\begin{array}{l}\text { I actively participate in the review } \\
\text { and development of prescribing } \\
\text { practice }\end{array}$ & $45 \%(n=111)$ & $44 \%(n=108)$ & $7.5 \%(n=19)$ & $2.5 \%(n=6)$ & 0 & $1 \%(n=2)$ \\
\hline $\begin{array}{l}\text { I understand and work within local } \\
\text { and national policies }\end{array}$ & $52.5 \%(n=129)$ & $45.5 \%(n=112)$ & $2 \%(n=5)$ & 0 & 0 & 0 \\
\hline $\begin{array}{l}\text { I know how to access relevant } \\
\text { information }\end{array}$ & $55 \%(n=135)$ & $42 \%(n=104)$ & $2 \%(n=5)$ & 0 & 0 & $1 \%(n=2)$ \\
\hline $\begin{array}{l}\text { I can critically appraise and apply } \\
\text { information in practice }\end{array}$ & $46.5 \%(n=114)$ & $48.5 \%(n=119)$ & $5 \%(n=13)$ & 0 & 0 & 0 \\
\hline $\begin{array}{l}\text { I work in partnership with colleagues } \\
\text { to benefit patients }\end{array}$ & $67 \%(n=164)$ & $32 \%(n=79)$ & $1 \%(n=3)$ & 0 & 0 & 0 \\
\hline $\begin{array}{l}\text { I an self-aware and confident in my } \\
\text { ability as a prescriber }\end{array}$ & $55.5 \%(n=137)$ & $42 \%(n=103)$ & $2.5 \%(n=6)$ & 0 & 0 & 0 \\
\hline
\end{tabular}


tice were asked to provide further details on the form that this support had taken. Fifty-nine per cent $(145 / 246)$ of the total number of respondents gave additional comments relating to other support received during the EFNP course. Providers of support were identified as pharmacists (42\% 104/246); peer support/other nurses (35\% 86/246); other medics $(11 \% 28 / 246)$; existing nurse prescribers/ nurse mentor (4\% 10/246).

\section{Experiences after the EFINP course: views on knowledge and competencies}

Respondents were asked whether there were any skills and knowledge needed in their prescribing practice that had not been covered by the EFNP course. Over half of respondents $(52 \% 127 / 246)$ felt that the course had covered the skills and knowledge required for practice. However, 40\% (99/ 246) stated that there were areas of skills and knowledge needed in practice which had not been covered by the course.

In total 48\% (119/246) of respondents provided further comments on the skills and knowledge they considered not fully covered by the course. While these produced a wide variety of opinion, five key themes emerged including: pharmacology issues; advanced clinical skills/examination skills/diagnostic skills; physical assessments; skills related to practice; information on formulary/BNF; and legal ethical issues (see Table 3).

Respondents were asked to consider a number of statements reflecting the prescribing competencies developed by the National Prescribing Centre (2001) and the extent to which they felt they had been able to maintain these competencies in their area of practice since qualifying as an EFNP. Findings are shown in Table 4.

Table 4 highlights that the vast majority of nurses agreed that they had been able to maintain these competencies in practice. For example, 99\% $(244 / 246)$ agreed or strongly agreed that they had up-to-date clinical knowledge, and 95\% (234/246) agreed or strongly agreed that they had up-to-date pharmacological knowledge.

With regard to the competency of being able to diagnose and generate treatment options (as shown in Table 4), respondents were asked elsewhere in the questionnaire to respond to a related Likert statement: 'I fear making an incorrect diagnosis'. Analysis showed that $23.5 \%$ (58/246) agreed and 4.5\% (11/246) strongly agreed with the statement; $46 \%(113 / 246)$ disagreed with this statement, 9\% $(22 / 246)$ strongly disagreed and $16 \%(39 / 246)$ responded that they were 'uncertain'.
Table 5 Nurse prescribers' CPD needs relating to prescribing

\begin{tabular}{ll}
\hline $\begin{array}{l}\text { Current professional } \\
\text { development needs }\end{array}$ & $\begin{array}{l}\text { No. (\%) of } \\
\text { responses } \\
(n=182)\end{array}$ \\
\hline Regular updates & $73(40 \%)$ \\
Training for formulary expansion & $25(13.5 \%)$ \\
CPD related to area of practice & $15(8 \%)$ \\
Local prescribing group meeting & $14(7.5 \%)$ \\
\hline${ }^{a}$ Top four responses only. &
\end{tabular}

\section{Experiences after the EFINP course: views on support and continuing professional development}

Sixty two per cent $(152 / 246)$ of respondents responded 'yes', they were currently receiving support or supervision for their role as an extended formulary nurse prescriber; 37\% (92/246) reported that they were not. Those nurse prescribers who reported receiving support/supervision were also asked to identify who provided this. Of those who specified, the majority $(67 \% 102 / 152)$ reported that this was provided by medical colleagues, $39 \%$ (59/152) reported support from other nurses, $24 \%$ (37/152) specified other nurse prescribers and pharmacists were cited as sources of support by $28 \%(43 / 152)$.

Nurse prescribers in the survey had been qualified as independent prescribers for between 6 and 12 months approximately. Nurses were asked whether they had undertaken any formal CPD relevant to their needs as prescribers since qualifying as a prescriber: $52 \%(127 / 246)$ reported that they had done so, and $48 \%(118 / 246)$ reported that they had not. The most common forms of CPD cited by respondents were supplementary prescribing 'top up' training $(37 \% 45 / 121)$, and events such as prescribing workshops/conferences/study days (20\% 24/121).

Greater numbers of respondents reported that they were 'able to engage in informal CPD such as private study and reading journals regularly': $95 \%(233 / 246)$ responded 'yes' to this item, and only $0.5 \%(1 / 246)$ responded 'no'.

Fifty seven per cent $(139 / 246)$ of the sample reported that they had 'current CPD needs in relation to nurse prescribing', 28\% (68/246) reported that they did not, and $8 \%(20 / 246)$ answered that they did not know. The five most frequently cited needs are outlined in Table 5.

As Table 5 indicates, many responses were nonspecific about the content of the CPD required ('regular updates'), whilst others were clear that they needed development concerned with the 
NPEF as it expanded to include more conditions and medicines, or CPD related to their area of prescribing practice.

\section{Discussion}

The findings from this national survey highlight a number of issues concerning the educational preparation and on-going professional development of nurse independent prescribers that warrant discussion in the light of the current health care policy and practice context.

The initial education programme of $25 \mathrm{HEl}$-based taught days was perceived to be satisfactory in meeting needs, at least to some extent, by the majority of the sample. This finding is encouraging, and suggests that the length, format and content of NMC approved programmes delivered by a range of $\mathrm{HEls}$ in England enables nurse prescribers to be adequately prepared for practice. Nevertheless, the reasons why a smaller minority of the sample did not consider that the course met their needs deserves further investigation. Some explanations may be found in other findings from the questionnaire (see below).

Previous research into the first wave of nurse prescribing in the United Kingdom had indicated that some nurses' pharmacology knowledge was inadequate for a prescribing role (While and Rees, 1993; Otway, 2001, 2002; Sodha et al., 2002a,b). In this study, pharmacology was the topic most prevalently studied as part of self-directed study by nurses in this survey, and was also the most frequently cited area of knowledge that was perceived not to have been covered sufficiently (in relation to knowledge needed for practice) within the initial preparatory programme of learning. This may be linked to the finding that approximately $16 \%(39 / 246)$ of the sample considered that the course had not meet their needs. It should be borne in mind that some of the nurses in this survey undertook education programmes over a three month period (as originally specified by the NMC), and not the currently recommended period of up to six months, and this may have led to respondents viewing the pharmacology content of programmes in this way. Although these findings may suggest deficiencies in nurses' pharmacology knowledge, it is significant that the vast majority of nurse prescribers in this survey, who had been qualified between 6 and 12 months approximately, considered that they had up-to-date pharmacological knowledge, and also reported that they were selfaware and confident in their prescribing practice.
Whilst inadequacies in nurse prescribers' pharmacology knowledge cannot be fully ruled out, due to the limitations of self-report data, findings from observation of nurses' prescribing practice reported elsewhere (Latter et al., 2005) indicated that there was little cause for concern about the clinical appropriateness of nurses' prescribing decisions, suggesting that EFNPs' levels of pharmacology knowledge were adequate for the medicines they are currently prescribing. It is possible that the nurse prescribers' emphasis on pharmacology learning reported in this study is a reflection of diligence and motivation to learn, rather than a reflection of inadequate knowledge per se.

The findings from this study also highlighted that the vast majority of nurse independent prescribers surveyed feel able to diagnose and generate treatment options and take personal responsibility for prescribing decisions. Whilst some anxiety about making an incorrect diagnosis was reported by a fairly small minority of the sample here, these reported competencies are in contrast to previous research (Luker et al., 1998; Baird, 2001) into district nurse and health visitor prescribers' feelings about their prescribing practice. It is likely that the positive findings of the study reported here are a reflection of the characteristics of the nurse prescribers in this study. Most were in senior nursing roles, such as nurse practitioners, and it is therefore likely that many of these nurses had previous clinical experience of diagnosis and a high degree of responsibility in their practice.

The finding that most nurses had received 12 days or more supervision from their designated supervising medical practitioner as part of their educational preparation for prescribing, and reported fairly high levels of satisfaction about this experience, with many positive comments about their medical mentors, is also encouraging. Many also continued to receive support and supervision for their prescribing practice from doctors after qualifying as prescribers. This finding provides evidence that doctors are actively engaged in supervising and supporting both trainee and qualified nurse prescribers and helps to counter claims (Baird, 2001) and previous research into district nurses' and health visitors' views of prescribing (Humphries and Green, 2000; Otway, 2002), which indicated that doctors were unaware or unsupportive of nurses' prescribing roles.

The positive findings concerning nurses' experiences of initial preparation for independent prescribing should however be viewed in light of the sample characteristics of this cohort of nurse prescribers. That is, as a group, they were working in senior clinical roles, and were well qualified aca- 
demically. This is indicative of good pre-existing knowledge and experience levels prior to embarking on the prescribing training programme. The majority of the sample were working in primary care in roles such as nurse practitioners and practice nurses. This indicates that these nurses were likely to be working in primary health care teams, with their designated supervising medical practitioner as part of such teams. Therefore, establishing working relationships and access to supervision time may have been facilitated by existing relationships with supervising doctors and/or ready on-site access to them. As the roll out of non-medical prescribing continues, to more nurses, pharmacists and allied health care professionals, levels of academic knowledge and clinical experiences of trainee prescribers are likely to become more diverse. A recent survey (Bradley et al., 2005) of 91 nurses training to be prescribers in 2003/4 in one University in England confirms this. Bradley et al found a lower prevalence of first degree (31\%) and postgraduate degree (14\%) qualifications in their sample in comparison to the qualifications of the sample in the study reported here. Access to supervising doctors may also become more difficult as both numbers of professionals requiring supervision increases, and as trainee prescribers include those working outwith explicit team structures (such as nurses working across GP practices in community specialist roles). The prohibitive work commitments of doctors creating difficulties for supervision was reported by some nurses in this study, and this may be compounded as the numbers and types of non-medical prescriber trainees increase in line with government policy.

The vast majority of nurses in this study reported that they were able to maintain a range of prescribing competencies in practice. The majority of nurses were acting in accordance with the Department of Health (2004) on CPD and were engaging in self-directed activities to maintain prescribing knowledge and skills. Two thirds were also receiving support and supervision for their prescribing practice from other health care professionals with whom they worked, including doctors, nurses and, to a lesser extent, pharmacists. Such activities may have been the main route by which these nurse prescribers were able to maintain their prescribing competencies, as access to formal CPD was reported as less universal, and, for many, CPD had taken the form of supplementary prescribing training, and was not therefore indicative of on-going CPD opportunities. Lack of access to CPD for prescribing nurses is highlighted by previous research into nurse prescribing (Otway, 2002), and is of concern, given the Department of
Health (2004) guidance on the CPD responsibilities of employers to provide access to education and training and also the importance that nurses place on it (Humphries and Green, 2000; Bradley and Nolan, 2004) in order to ensure safe and effective prescribing practice. Findings from the study reported elsewhere (Latter et al., 2005) highlighted that organizational supports for nurses who are prescribing may be lacking in a number of respects: some nurses in primary care still do not have access to computer-generated scripts which they perceive to be limiting to their prescribing practice, access to Prescription Analysis and Costs Data (PACT) data for nurses working in primary care in this study was also far from universal. The limited access to formal CPD highlighted in this study may have been a function of the timing of the survey: that is, the majority of the nurses in the sample had only been qualified for between 6 and 12 months approximately, and it may be that their needs for and consequent access to CPD will increase as time goes on. However, the findings do suggest that there is no room for complacency and that action is required at an organizational level, through for example, the leadership and direction of nurse prescribing leads in Strategic Health Authorities, PCTs and NHS Trusts to ensure that nurse prescribers in employing trusts are able to regularly update the knowledge and skills that should underpin safe and effective prescribing practice.

\section{Conclusion}

This first national survey of the education and professional development experiences of nurse independent prescribers in England provides evidence which highlights areas in which national policy is working well, and also points up issues which may need addressing as the roll out of nurse prescribing continues. In evaluating the current model of educational preparation and forms of CPD for nurse prescribers in England, the findings highlight characteristics of programmes that health care policy makers and nurse educationalists internationally may wish to consider in developing and refining nurse prescriber education programmes in their respective countries across the world.

\section{Study limitations}

This paper reports findings that are based on nurses' self-reported views of their prescribing education and practice. As indicated above, the findings also need to be viewed in light of the 
timing of the survey: the sample targeted nurse prescribers who had qualified within approximately 18 months of the introduction of independent nurse prescribing, and this may have resulted in particular educational experiences that may or may not be typical of later cohorts of trainee nurse prescribers. Additionally, nurses in this survey had only been qualified for between 6 and 12 months approximately at the time of the survey, and this may also have influenced the extent to which they had experienced access to CPD opportunities. Further research into on-going education and CPD experiences of non-medical prescribers is recommended.

\section{Acknowledgements}

This study was commissioned by the Policy Research Programme at the Department of Health in England. Any views expressed are those of the authors and not necessarily those of the Department of Health. Molly Courtenay contributed to data collection tools and processes.

\section{References}

Avery, A., Pringle, M., 2005. Extended prescribing by UK nurses and pharmacists. British Medical Journal 331, $1154-1155$.

Avery, A., Savelyich, S., Wright, L., 2004. Doctors' views on supervising nurse prescribers. Prescriber, September 5, 5661.

Baird, 2001. Diagnosis and prescribing: the impact of nurse prescribing on professional roles. Primary Health Care 11 (5), 24-26.

Bradley, E., Nolan, P., 2004. The progress of nurse prescribing: a commentary. Nurse Prescribing 2 (4), 148-151.

Bradley, E., Campbell, P., Nolan, P., 2005. Nurse prescribers: who are they and how do they perceive their role?. Journal of Advanced Nursing 51 (5) 439-448.

Brooks, N., Otway, C., Rashid, C., Kilty, E., Maggs, C., 2001. The patients' view: the benefits and limitations of nurse prescribing. British Journal of Community Nursing 6 (7), 342348.

Buchan, J., Calman, L., 2004. Implementing nurse prescribing: an updated review of current practice internationally. International Council of Nurses, Geneva.
Department of Health, 2002. Extending Independent Nurse Prescribing within the NHS in England: a Guide for Implementation, first ed. Department of Health, London.

Department of Health, 2003. Supplementary Prescribing by Nurses and Pharmacists within the NHS in England: a Guide for Implementation. Department of Health, London.

Department of Health, 2004. Extending Independent Nurse Prescribing within the NHS in England: a Guide for Implementation, second ed. Department of Health, London.

DePoy, E., Gitlin, L.N., 1994. Introduction to Research: Multiple Strategies for Health and Human Research. Mosby, St. Louis

Harris, J., Taylor, J., Mackie, C., 2004. Research Literature Review on Prescribing. Scottish Executive Social Research, Edinburgh.

Humphries, J.L., Green, E., 2000. Nurse prescribers: infrastructures required to support their role. Nursing Standard 14 (48), 35-39.

Latter, S., Courtenay, M., 2004. Effectiveness of nurse prescribing: a review of the literature. Journal of Clinical Nursing 13, 26-32.

Latter, S., Maben, J., Myall, M., Young, A., Courtenay, M., Dunn, N., 2005. An evaluation of extended formulary extended independent nurse prescribing. Final Report, School of Nursing \& Midwifery, University of Southampton.

Luker, K., Austin, L., Willock, J., Ferguson, B., Smith, K., 1997. Nurses' and GPs' views of the nurse prescribers' formulary. Nursing Standard 11 (22), 33-38.

Luker, K., Austin, L., Hogg, C., Ferguson, R., Smith, K., 1998. Nurse-patient relationships: the context of nurse prescribing. Journal of Advanced Nursing 28 (2), 235-242.

National Prescribing Centre, 2001. An Outline Framework to Help Nurse Prescribers. National Prescribing Centre, Liverpool.

Nursing and Midwifery Council, 2006. Standards of Proficiency for Nurse and Midwife Prescribers. Nursing and Midwifery Council, London.

Otway, C., 2001. Informal peer support: a key to success for nurse prescribers. British Journal of Community Nursing 6 (11), 586-591.

Otway, C., 2002. The development needs of nurse prescribers. Nursing Standard 16 (18), 33-38.

Royal College of Nursing, 1998. Research Ethics: Guidance for Nurses Involved in Research or Nay Other Investigative Project Involving Human Subjects. RCN, London.

Sodha, M., McLaughlin, M., Williams, G., Dhillon, S., 2002a. Nurses' confidence and pahramcological knowledge: a study. British Journal of Community Nursing 7 (6), 309315.

Sodha, M., Williams, G., Shah, R., Clegg, J., 2002b. Nurse prescribing - testing the knowledge base. Journal of Community Nursing 16 (3), 4-14.

While, A., Rees, K.L., 1993. The knowledge base of health visitors and district nurses regarding products in the proposed formulary for nurse prescription. Journal of Advanced Nursing 18 (10), 1573-1577.

Available online at www.sciencedirect.com 